\title{
"You Will Find Out When the Time Is Right": Boys, Men, and Menstruation
}

\author{
Mindy J. Erchull
}

The majority of menstruators are women-although not all women menstruate and not all menstruators are women. Given this, it is not surprising that there has been little focus on the attitudes about and experiences with menstruation among men. This chapter reviews the research about menstruation and boys and men who are not themselves menstruators in order to shed light on how they learn about menstruation, what they actually know about menstruation, and what beliefs and attitudes boys and men hold about both menstruation and menstruators. It is important to note that nearly all of the research in this area reflects an underlying assumption of a gender binary. Because of this, binary gendered language is often used in this chapter to reflect the nature of the research that has been done. Moreover, this chapter focuses cisgender boys and men. While a critically important topic to study, the experiences of men and non-binary people who menstruate is not covered in this chapter-largely because, to date, there is little academic work on this topic (for notable exceptions, see Chrisler et al. 2016; Fahs 2016; Rydström, this volume; Frank and Dellaria, this volume).

\section{Education About Menstruation}

Menstruation is typically framed as a normal, natural biological process, but at the same time, it is also framed as a process that should be kept private or secret-particularly from boys and men (Stubbs 2008; White 2013). This ambivalent cultural context is the backdrop in which girls and boys learn about menstruation, and it continues to influence the beliefs and attitudes of women and men throughout their lives. While girls are seen as those who need to know about menstruation because they will, typically, experience it, 
nonetheless, many adolescent girls included in one study in the United States reported feeling unprepared for menarche (White 2013). Research performed in the United States indicates that mothers are a primary source of information about menstruation for girls, but they also learn about menstruation from their peers, the media, and school-based health education programsthe latter of which are often gender segregated (Allen, Kaestle, and Goldberg 2011; Fingerson 2005; Koff and Rierdan 1995; Lee 2008). Also, other research from the United States has shown that some girls report not feeling well-educated about or prepared for menarche (Cooper and Koch 2007; Costos, Ackerman, and Paradis 2002). Even when girls report receiving information about the biology of menstruation and how to manage it hygienically, they want additional information about more subjective aspects of menstruation such as how menstruation feels physically (Koff and Rierdan 1995).

Like girls, boys in the United States typically report incomplete and/or inaccurate knowledge about menstruation, and boys generally receive less education about menstruation than do girls (Allen, Kaestle, and Goldberg 2011). Research from Taiwan (Chang, Hayter, and Lin 2012), the U.K. (Lovering 1995), and Australia (Peranovic and Bentley 2017) indicates that gender-segregated health and sexual education curricula rarely include menstruation in the content covered with boys. Even when these programs are not gender segregated as was the experience in a sample of participants from New Zealand, the information provided about female pubertal development and menstruation is often framed less positively than is true for the information about male pubertal development (Diorio and Munro 2000). Of course, formal education programs are not the only place boys learn about menstruation. Research conducted in the United Sates (Allen, Kaestle, and Goldberg 2011) and the U.K. (Lovering 1995) shows that, like girls, boys sometimes learn about menstruation from their mothers. Research more broadly about sexual education in the United States indicates that peers and the media are often key sources of information for boys (Epstein and Ward 2008).

When boys do learn about menstruation, they often report gaining knowledge in relatively informal ways. David Linton (2019) described a theme that emerged from his discussions about menstruation with men: They often first encountered menstruation through a "mysterious incident" or "encounter that left them asking, "What's going on here? What am I not supposed to know?"” (Linton 2019, 8). For example, in one study, some young men from the U.S. reported having learned about menstruation for the first time when a sister experienced menarche (Allen, Kaestle, and Goldberg 2011). This does not mean that they were actually learning a great deal, however. For example, one participant recalled being frightened when his sister had her first period and had "a huge blood stain in the back of her night clothes" (Allen, Kaestle, and Goldberg 2011, 139). When he subsequently asked his mother for more information, "she only stated that 'you will find out when the time is right"' (139). In another study conducted in the United States, boys reported learning about menstruation through overhearing discussions among female 
friends and classmates (Fingerson 2005). Men in both the United States (Allen and Goldberg 2009; Allen, Kaestle, and Goldberg 2011; Erchull and Richmond 2015) and Australia (Peranovic and Bentley 2017) often report that they learned information about menstruation from sexual and romantic partners. One Australian man said that "if a man lives with a female partner he needs to understand as much as it is possible about all aspects of her life including menstruation" (Peranovic and Bentley 2017, 120). A participant in another study from the United States discussed how he learned about menstruation in order to help identify when his partner would be most likely to conceive when they decided to have a child (Allen, Kaestle, and Goldberg 2011).

Given the lack of education boys receive about menstruation, the fact that research consistently shows that men report feeling less knowledgeable about menstruation than women is to be expected. Studies done in the United States (Brooks-Gunn and Ruble 1986) and Italy (Amann-Gainotti 1986) in the 1980s indicated that adolescent boys and young men generally reported learning less about menstruation than female peers reported, and they often did not hold an accurate understanding of what menstruation was and how it worked. For example, they might understand that it involves blood coming out of the vagina, but they might attribute to something other than the shedding of the uterine lining, such as "the breaking of the ovaries" or to expel a harmful microbe (Amann-Gainotti 1986, 706). In other cases, they may misunderstand even more of what is involved as was the case with a 14-year-old boy who thought that menstruating involved urinating "blood because the bladder breaks" (Amann-Gainotti 1986, 706).

Similar findings about cursory and inaccurate knowledge about menstruation have since been found in studies with samples from around the globe. High school boys in the United States were described in one study as "half-knowing" about menstruation where they were familiar with it but were unsure of the details such as the differences between pads and tampons or the PMS stood for premenstrual syndrome rather than post-menstrual syndrome (Fingerson 2005, 101). In part because of receiving information from myriad informal sources, a number of participants in one study of male undergraduate students in the U.S. reported that they "pieced together" information about menstruation as children and adolescents (Allen, Kaestle, and Goldberg $2011,141)$. In a study of junior high school students in Taiwan, despite most of the male participants being familiar with menstruation, they had less accurate knowledge of menstruation than did their female peers, and they were more likely to endorse cultural myths about menstruation and restrictions on menstruating girls and women (Cheng, Yang, and Liou 2007). These included not eating or drinking iced foods or going to temple while menstruating. Similarly, in another study of Taiwanese early adolescents, boys reported a lack of knowledge and held misinformation about menstruation including that girls have periods every one to two weeks, that menstrual fluid is comprised of "blood, ovum and ... sperm," and that when girls 
"have their periods, they can give both to a baby by themselves" (Chang, Hayter, and Lin 2012, 517).

Research conducted in Australia, however, does indicate that men do often encounter, and even seek out, additional information about menstruation as they get older (Peranovic and Bentley 2017). Much of this added knowledge seems to come from discussions with female partners as was the case with a sample of participants from the United States (Allen, Kaestle, and Goldberg 2011). Given this, it is not clear that men actually know more about menstruation through these types of discussions. It may well be that they are just more familiar with menstruation. Other research conducted in Brazil (Caçapava Rodolpho et al. 2016) and the U.K. (Liao, Lunn, and Baker 2015) focusing specifically on the experiences of men with female partners in perimenopause indicates that there is still a lack of knowledge. Men reported that they were only familiar with menopause in general terms and lacked key information. Some men did, however, feel that they had a responsibility to seek out information about menopause to be better able to support their partners. However, this is another case where men are haphazardly piecing together information from a number of, largely informal, sources.

\section{Beliefs and Attitudes About Menstruation}

Among girls and women, lack of knowledge about and inadequate preparation for menstruation has been shown to be related to more ambivalent and negative attitudes about menstruation in both Italy and the United States (for example, Amann-Gainotti 1986; Scott et al. 1989; White 2013). Given that boys and men typically receive less education about menstruation and have less accurate knowledge, it should be unsurprising that negative beliefs and attitudes are commonly found in research done with diverse groups of participants. For example, older research from the United States showed that college men were more likely to perceive menstruation as debilitating than was true of their female peers (Brooks-Gunn and Ruble 1980, 1986). Other older research conducted in the United States showed that negative attitudes were even held by young adolescent boys and that these were more negative than those of their female peers who had begun to menstruate (Clarke and Ruble 1978). However, another third older study conducted in the United States showed that, while younger men were more likely to view menstruation as debilitating than young women, there was no such gender difference found for an older sample (Chrisler 1988). So, while these negative attitudes may develop early, they may also soften as men age and gain more knowledge of and experience with menstruation.

More recent research with samples from throughout the world have shown a similar pattern of more negative attitudes being held by men than by women. Specifically, in a sample of young adults from the United States, men more strongly endorsed the idea that menstruation requires secrecy than did women (Marván et al. 2006). They also more strongly endorsed the 
idea that there are things women should and should not during menstruation. Research with Mexican samples has also shown that men are more likely than women to view menstruation negatively, but like the earlier research by Chrisler (1988) in the United States, these negative views were more pronounced for younger rather than older men (Marván, Cortés-Iniestra, and González 2005; Marván et al. 2006). Research conducted in East Asia also shows similar patterns. Male adolescents in Taiwan reported more negative attitudes about menstruation than did their female peers (Cheng, Yang, and Liou 2007). In a study of Chinese undergraduates in Hong Kong, men more strongly endorsed the idea that menstruation should be kept secret than women, but they were actually less likely than the women in the sample to view menstruation as disabling (Wong et al. 2013).

\section{Beliefs and Attitudes About Menstruators}

It has been suggested that men's attitudes are particularly important factors to consider in relation to the perpetuation and dissemination of stereotypes about menstruation and menstruators (Fromme and Emihovich 1998). Menstrual ideologies do both reflect and reinforce patriarchal social structures privileging men and boys, and research shows that boys start using menstruation as a means of asserting dominance when they are young. Research conducted in both New Zealand (Diorio and Munro 2000) and the U.K. (Lovering 1995) indicate that this is largely done through teasing and ridiculing girls about their periods. This is not a practice limited to young boys, however. More research conducted in the U.K. suggests that explicit teasing transitions to jokes about menstruation or menstruating women in general (Newton 2016). These jokes, however, often center on menstruating women being unclean or disgusting and can serve to reinforce a patriarchal gender hierarchy.

Research conducted in both Mexico and the United States has also shown that negative attitudes about menstruators are related to endorsement of sexist ideologies-particularly hostile sexism which involves explicitly negative attitudes about women and beliefs about female inferiority-among both female and male participants (Chrisler et al. 2014; Forbes et al. 2003). Both women and men also seem to evaluate women perceived as menstruating negatively. In one study conducted in the United States, a female confederate dropped either a wrapped, unused tampon, or a hairclip in the presence of a participant (Roberts et al. 2002). Confederates who dropped a tampon were subsequently rated as both less competent and less likable than those who dropped a hairclip. Women seem to anticipate this type of negative evaluation. In another study using a United States sample, female participants who were menstruating and thought a male confederate was aware of their menstrual status believed that he liked them less than was true for both participants who thought he did not know that they were menstruating or participants who were not menstruating (Kowalski and Chapple 2000). 
These negative evaluations of women are made in a cultural context where negative attitudes and stereotypes about menstruation and menstruators are common. As demonstrated in a study conducted in Australia, many cultural stereotypes surrounding menstruation involve beliefs about excessive emotionality and pain being part of menstruation-experiences that are typically viewed negatively and as undesirable (Christensen and Oei 1990). Generally, pain is perceived as part of the experience of menstruation, and men's beliefs about this are reflected in the findings reviewed above where men are generally more likely than women to perceive menstruation as debilitating. Emotionality, however, is generally more strongly connected to beliefs about the premenstrual phase of the menstrual cycle and is generally thought of as a core component of premenstrual syndrome (PMS; Chrisler and Gorman 2015).

Western cultures, in particular, hold a medicalized view of premenstrual changes women may experience (Chrisler and Gorman 2015). Both women and men endorse this perspective, but stereotypical views about premenstrual women seem to be a key part of men's understanding of menstruation. Men often view PMS as an excuse women make use of to avoid unwanted tasks or to excuse emotional reactivity (King, Ussher, and Perz 2014; Newton 2016; Reberte et al. 2014; Ussher and Perz 2013). In one study conducted in the U.K., men reported that they often heard other men attribute women's anger, frustration, or general emotionality to "that time of the month," implying menstruation or being in the premenstrual phase (Laws 1992, 125). They also reported being aware of these types of menstrual cycle-related changes in their female partners. It is also not uncommon for women to be explicitly asked, often by men, if they are on the rag or if it's that time of the month when they react emotionally, as was found in reports from a different sample of participants from the U.K. (Newton 2016). While both women and men use these phrases, there is a negative and dismissive quality to the way they are often used by men. However, some men did indicate that this type of thinking was reductionist and served to dismiss women's actual concerns and experiences (Laws 1992). Moreover, research conducted in Brazil and Australia indicates that some men do see the premenstrual and menstrual phases as well as perimenopause as times when it is important to be particularly supportive of their partners (Caçapava Rodolpho et al. 2016; King, Ussher, and Perz 2014; Reberte et al. 2014).

\section{Dis/Comfort with Menstruation}

An underlying theme in much of the research about boys, men, and menstruation is the idea that not only is menstruation not a domain for men, it is not a topic with which they are comfortable. Given this, menstruation should be discussed and handled discreetly among women. Both Sophie Laws (1992) an David Linton (2019) have described this pattern of keeping menstruation outside of men's attention as part of the etiquette of menstruation. Boys, such as those included in a study conducted in Taiwan, have described 
learning about menstruation as uncomfortable and embarrassing (Chang, Hayter, and Lin 2012). This discomfort does not necessarily go away as boys mature, however. For examples, while some Australian men in one study reported that they had developed a comfort with discussing menstruation and viewed it as "no big deal," others reported continued discomfort with the topic (Peranovic and Bentley 2017, 119). Other men did not see it as something they need to know about or be involved with.

For men who report comfort with menstruation as part of research conducted in the United States and Australia, intimate relationships with women are often discussed as part of developing this attitude (Allen, Kaestle, and Goldberg 2011; Peranovic and Bentley 2017). They learn more about menstruation from their partners, but they also just come to see menstruation as more normal and routine. While comfort with menstruation may be part of some men's intimate relationships, that is not the case for all men, however. Some men from United States and U.K. samples still expect their partners to conceal evidence of menstruation from them (Allen, Kaestle, and Goldberg 2011; Laws 1992).

A specific context where this dichotomy shows up is sexual contact during menstruation. For men who are uncomfortable talking about menstruation or seeing evidence that menstruation happens (for example, pads and tampons), disgust is often a common reaction to the idea of coming into contact with menstrual fluid. As one man from a United States sample put it, "the idea of getting menstrual blood on me horrifies me" (Allen, Kaestle, and Goldberg 2011, 147). In a study conducted in the United States, men reported being concerned with the messiness inherent in menstrual sex, but they also reported that engaging in this behavior was shameful-particularly for the menstruating women (Allen and Goldberg 2009). However in multiple studies conducted in the United States, women do report desiring and having sex during menstruation even though actual rates of sexual activity go down during this phase compared to others across the menstrual cycle (Fahs 2011; Hensel, Fortenberry, and Orr 2007). However, some of the reason why women do not have sex with men while menstruating may be due to their concerns about disgusting or discomforting male partners (Fahs 2011). For men in a United States sample who did report having menstrual sex regularly, they talked about it as a sign of maturation and viewed it as part of being in a trusting and caring intimate relationship (Allen and Goldberg 2009).

\section{The Special Case of Fathers}

While intimate relationships are one context in which men are often confronted with menstruation, parenting is another such context. Research conducted in both Australia and the United States indicated that fathers generally struggle to talk with their children about sexuality and sexual health (Kirkman, Rosenthal, and Feldman 2002; Wright 2009). There is often a gendered division of labor in how these conversations are handled where 
mothers are expected to talk with daughters and fathers are expected to talk with sons. In a United States sample, fathers often reported that menstruation was a topic they are not in a good position to discuss because it was outside of their own experience (Wilson, Dalberth, and Koo 2010). As was found with an Australian sample, however, some men do believe that they need to understand menstruation so that they can take an active role in parenting their children and educating both daughters and sons about menstruation (Peranovic and Bentley 2017). Other research conducted in the United States has found that menstruation was generally part of discussions between mothers and daughters but not fathers and daughters, and it was not part of discussions between either mothers or fathers with sons (Wyckoff et al. 2008).

Fathers can find themselves facing a paradox: their daughters may want their support and want them to be open if daughters want to talk, but they are also uncomfortable actually talking about menstruation with them (Koff and Rierdan 1995). Research conducted in North America does show that girls generally do not talk with their fathers about menstruation and that they may even avoid their fathers starting at menarche (Koff and Rierdan 1995; Uskul 2004). Research conducted in Canada showed that when mothers told fathers about their daughters beginning to menstruate, some girls became upset (Uskul 2004), and daughters in a United States sample reported embarrassment when their fathers tried to make celebratory gestures related to the experience of menarche (Chrisler and Zittel 1998). Not all girls have or live with mothers, however, so single, custodial, and gay fathers cannot necessarily foist menstruation-related interactions onto a female co-parent. Given this, they can find themselves being the parent who is present to provide education about and support around menstruation despite the discomfort both they and their daughters might experience. Girls still may not have these interactions with their fathers, however. In a study conducted in the United States, girls not living with their mothers reported having to wait to get information until they could talk with their mother or another woman with whom they were close, such as a grandmother or older sister (Kalman 2003). They generally reported embarrassment discussing menstruation with their fathers, but for girls who did not have ready access to a woman to talk with, they would talk with their fathers despite reporting discomfort with the process.

While daughters may be uncomfortable talking about menstruation with their fathers, sons just generally do not receive much information about menstruation from either mothers or fathers (Brooks-Gunn and Ruble 1986; Wyckoff et al. 2008). One study conducted in the United States has specifically explored fathers' attitudes about and experiences with educating both their sons and daughters about menstruation (Erchull and Richmond 2015). The fathers in this study did believe that fathers were important sources of information for both sons and daughters (ranked 6th and 10th out of 20 sources, respectively), but they saw themselves as a significantly more important source of this information for their sons. They did not report different 
levels of comfort with talking to sons and daughters about menstruation, however. That said, there were some differences in what fathers reported as part of these conversations. With daughters, there was a greater focus on positive framing of menstruation, and it was only in regard to talking to their daughters that fathers mentioned avoidance. With sons, fathers were more likely to mention including a discussion of mood swings, and it was only with sons that they reported focusing on having empathy for menstruators as well as providing advice for how to cope with menstruators.

\section{Where Do We Go from Here?}

Overall, while there is some consistency in the research findings, there is actually very little research about boys, men, and menstruation to draw on. More research is needed to gain a better understanding of what boys and men actually know about menstruation, how they have gained that knowledge, and how this relates to their attitudes and behaviors. At the heart of this is a problematic cycle where menstruation is viewed as the purview of women, so men are perceived as being uncomfortable with the topic. It is also seen as unimportant to educate men about menstruation in much detail because it is not something they are expected to deal with. This lack of knowledge can contribute to stereotypical beliefs, negative attitudes, and general discomfort. This cycle needs to be interrupted.

Even looking beyond the fact that some men menstruate and not all women do, men do interact with menstruators. They have mothers and sisters who do or did menstruate. They may have partners who menstruate. They parent daughters who do or will menstruate. They share communities with menstruators. When people, regardless of gender identity, understand what menstruation is, what is involved in the menstrual cycle, and how it can (and does not) impact women, menstruation can truly be made normative rather than just being framed in education contexts as a normal biological process that then needs to not be discussed publically because it is taboo. Most men may not menstruate, but knowledge can facilitate comfort, and comfort can facilitate open discussion, and openness can facilitate cultural positivity.

\section{REFERENCES}

Allen, Katherine R., and Abbie E. Goldberg. 2009. "Sexual Activity during Menstruation: A Qualitative Study." Journal of Sex Research 46 (6): 535-45. https://doi.org/10.1080/00224490902878977.

Allen, Katherine R., Christine E. Kaestle, and Abbie E. Goldberg. 2011. "More Than Just a Punctuation Mark: How Boys and Young Men Learn about Menstruation." Journal of Family Issues 32 (2): 129-56. https://doi.org/10.1177/ $0192513 X 10371609$.

Amann-Gainotti, Merete. 1986. "Sexual Socialization during Early Adolescence: The Menarche." Adolescence 21 (83): 703-10. 
Brooks-Gunn, Jeanne, and Diane N. Ruble. 1980. "The Menstrual Attitude Questionnaire." Psychosomatic Medicine 42 (5): 503-12. https://doi.org/10. 1097/00006842-198009000-00005.

1986. "Men's and Women's Attitudes and Beliefs about the Menstrual Cycle." Sex Roles 14 (5-6): 287-99. https://doi.org/10.1007/BF00287580.

Caçapava Rodolpho, Juliana Reale, Bruna Cid Quirino, Luiza Akiko Komura Hoga, and Patrícia Lima Ferreira Santa Rosa. 2016. "Men's Perceptions and Attitudes toward Their Wives Experiencing Menopause." Journal of Women \& Aging 28 (4): 322-33. https://doi.org/10.1080/08952841.2015.1017430.

Chang, Yu-Ting, Mark Hayter, and Mei-Ling Lin. 2012. "Pubescent Male Students' Attitudes towards Menstruation in Taiwan: Implications for Reproductive Health Education and School Nursing Practice." Journal of Clinical Nursing 21 (3-4): 513-21. https://doi.org/10.1111/j.1365-2702.2011.03700.x.

Cheng, Ching-Yu, Kyeongra Yang, and Shwu-Ru Liou. 2007. "Taiwanese Adolescents' Gender Differences in Knowledge and Attitudes towards Menstruation." Nursing \& Health Sciences9 (2): 127-34. https://doi.org/10.1111/j.1442-2018. 2007.00312.x.

Chrisler, Joan C. 1988. "Age, Gender-Role Orientation, and Attitudes toward Menstruation." Psychological Reports 63 (3): 827-34. https://doi.org/10.2466/ pr0.1988.63.3.827.

Chrisler, Joan, C., and Carolyn B. Zittel. 1998. "Menarche Stories: Reminiscences of College Students from Lithuania, Malaysia, Sudan, and the United States." Health Care for Women International 19 (4): 303-12. https://doi.org/ $10.1080 / 073993398246287$.

Chrisler, Joan C., and Jennifer A. Gorman. 2015. "The Medicalization of Women's Moods: Premenstrual Syndrome and Premenstrual Dysphoric Disorder." In The Wrong Prescription for Women: How Medicine and Media Create a "Need" for Treatments, Drugs, and Surgery, edited by Maureen C. McHugh and Joan C. Chrisler, 77-98. Santa Barbara, CA: Praeger.

Chrisler, Joan C., Jennifer A. Gorman, Jen Manion, Michael Murgo, Angela Barney, Alexis Adams-Clark, Jessica R. Newton, and Meaghan McGrath. 2016. "Queer Periods: Attitudes toward and Experiences with Menstruation in the Masculine of Centre and Transgender Community." Culture, Health or Sexuality 18 (11): 123850. https://doi.org/10.1080/13691058.2016.1182645.

Chrisler, Joan C., Jennifer A. Gorman, Maria Luisa Marván, and Ingrid Johnston-Robledo. 2014. "Ambivalent Sexism and Attitudes toward Women in Different Stages of Reproductive Life: A Semantic, Cross-Cultural Approach." Health Care for Women International 35 (6): 634-57. https://doi.org/10.1080/07399332 .2012.740113.

Christensen, A. P., and T. P. S. Oei. 1990. "Men's Perception of Premenstrual Changes on the Premenstrual Assessment Form." Psychological Reports 66 (2): 615-19. https://doi.org/10.2466/pr0.1990.66.2.615

Clarke, Anne E., and Diane N. Ruble. 1978. "Young Adolescents' Beliefs Concerning Menstruation." Child Development 49 (1): 231-34. https://doi. org/10.2307/1128615.

Cooper, Spring Chenoa, and Patricia Barthalow Koch. 2007. "'Nobody Told Me Nothin': Communication about Menstruation among Low-income African American Women.” Women \& Health 46 (1): 57-78. https://doi.org/10.1300/ J013v46n01_05. 
Costos, Daryl, Ruthie Ackerman, and Lisa Paradis. 2002. "Recollections of Menarche: Communication between Mothers and Daughters Regarding Menstruation." Sex Roles 46 (1-2): 49-59. https://doi.org/10.1023/A:1016037618567.

Diorio, Joseph A., and Jennifer A. Munro. 2000. "Doing Harm in the Name of Protection: Menstruation as a Topic for Sex Education." Gender and Education 12 (3): 347-365.

Epstein, Marina, and L. Monique Ward. 2008. “'Always Use Protection': Communication Boys Receive about Sex from Parents, Peers, and the Media." Journal of Youth and Adolescence 37(2): 113-26. https://doi.org/10.1007/ s10964-007-9187-1.

Erchull, Mindy J., and Katherine Richmond. 2015. “'It's Normal... Mom Will Be Home in an Hour': The Role of Fathers in Menstrual Education." Women's Reproductive Health 2 (2): 93-110. https://doi.org/10.1080/23293691.2015.1 089149.

Fahs, Breanne. 2011. "Sex during Menstruation: Race, Sexual Identity, and Women's Accounts of Pleasure and Disgust." Feminism \& Psychology 21 (2): 155-78. https://doi.org/10.1177/0959353510396674.

- 2016. Out for Blood: Essays on Menstruation and Resistance. Albany, NY: SUNY Press.

Fingerson, Laura. 2005. "Agency and the Body in Adolescent Menstrual Talk." Childhood 12 (1): 91-110. https://doi.org/10.1177/0907568205049894.

Forbes, Gordon B., Leah E. Adams-Curtis, Kay B. White, and Katie M. Holmgren. 2003. "The Role of Hostile and Benevolent Sexism in Women's and Men's Perceptions of the Menstruating Woman.” Psychology of Women Quarterly 27 (1): 58-63. https://doi.org/10.1111/1471-6402.t01-2-00007.

Fromme, Rebecca E., and Catherine Emihovich. 1998. "Boys Will be Boys: Young Males' Perceptions of Women, Sexuality, and Prevention." Education and Urban Society 30 (2): 172-88. https://doi.org/10.1177/0013124598030002003.

Hensel, Devon J., J. Dennis Fortenberry, and Donald P. Orr. 2007. "Situational and Relational Factors Associated with Coitus during Vaginal Bleeding among Adolescent Women." Journal of Sex Research 44 (3): 269-77. https://doi. org/10.1080/00224490701443940.

Kalman, Melanie. 2003. "Taking a Different Path: Menstrual Preparation for Adolescent Girls Living Apart from Their Mothers." Health Care for Women International 24 (10): 868-79. https://doi.org/10.1080/07399330390244275.

King, Marlee, Jane M. Ussher, and Janette Perz. 2014. "Representations of PMS and Premenstrual Women in Men's Accounts: An Analysis of Online Posts from PMSBuddy.com." Women's Reproductive Health l (1) 3-20. https://doi.org/10.1 080/23293691.2014.901796.

Kirkman, Maggie, Doreen A. Rosenthal, and S. Shirley Feldman. 2002. "Talking to a Tiger: Fathers Reveal Their Difficulties in Communicating about Sexuality with Adolescents." New Directions for Child and Adolescent Development 2002 (97): 57-74. https://doi.org/10.1002/cd.50.

Koff, Elissa, and Jill Rierdan. 1995. "Preparing Girls for Menstruation: Recommendations from Adolescent Girls." Adolescence 30 (120): 795-812.

Kowalski, Robin M., and Tracy Chapple. 2000. "The Social Stigma of Menstruation: Fact or Fiction?" Psychology of Women Quarterly 24 (1): 74-80. https://doi. org/10.1111/j.1471-6402.2000.tb01023.x.

Laws, Sophie. 1992. "'It's Just the Monthlies, She'll Get over It': Menstrual Problems and Men's Attitudes." Journal of Reproductive and Infant Psychology 10 (2): 117 28. https://doi.org/10.1080/02646839208403944. 
Lee, Janet. 2008. "A Kotex and a Smile' Mothers and Daughters at Menarche." Journal of Family Issues 29 (10): 1325-47. https://doi.org/10.1177 /0192513X08316117.

Liao, Lih-Mei, Sarah Lunn, and Martyn Baker. 2015. "Midlife Menopause: Male Partners Talking." Sexual and Relationship Therapy 30 (1): 167-80. https://doi. org/10.1080/14681994.2014.893290.

Linton, David. 2019. Men and Menstruation: A Social Transaction. New York, NY: Peter Lang.

Lovering, Kathryn Matthews. 1995. “The Bleeding Body: Adolescents Talk about Menstruation." In Feminism and Discourse: Psychological Perspectives, edited by Sue Wilkinson and Celia Kitzinger, 10-31. Thousand Oaks, CA: Sage.

Marván, Ma Luisa, Dyana Ramírez-Esparza, Sandra Cortés-Iniestra, and Joan C. Chrisler. 2006. "Development of a New Scale to Measure Beliefs about and Attitudes toward Menstruation (BATM): Data from Mexico and the United States." Health Care for Women International 27 (5): 453-73. https://doi. org/10.1080/07399330600629658.

Marván, Maria Luisa, Sandra Cortés-Iniestra, and Regina González. 2005. "Beliefs about and Attitudes toward Menstruation among Young and Middle-Aged Mexicans." Sex Roles 53 (3-4): 273-79. https://doi.org/10.1007/s11199-0055685-3.

Newton, Victoria Louise. 2016. Everyday Discourses of Menstruation: Cultural and Social Perspectives. London: Palgrave Macmillan.

Peranovic, Tamara, and Brenda Bentley. 2017. "Men and Menstruation: A Qualitative Exploration of Beliefs, Attitudes and Experiences." Sex Roles 77 (1-2): 113-24. https://doi.org/10.1007/s11199-016-0701-3.

Reberte, Luciana Magnoni, José Henrique Cogo de Andrade, Luiza Akiko Komura Hoga, Trudy Rudge, and Juliana Reale Caçapava Rodolpho. 2014. "Men's Perceptions and Attitudes toward the Partner with Premenstrual Syndrome." American Journal of Men's Health 8 (2): 137-47. https://doi. org/10.1177/1557988313497050.

Roberts, T. A., J. L. Goldenberg, C. Power, and T. Pyszczynski, T. 2002. "'Feminine Protection': The Effects of Menstruation on Attitudes towards Women." Psychology of Women Quarterly26 (2): 131-39. https://doi.org/10.1111/1471-6402. 00051 .

Scott, Clarissa S., Danette Arthur, Maria Isabel Panizo, and Roger Owen. 1989. "Menarche: The Black American Experience." Journal of Adolescent Health Care 10 (5): 363-68. https://doi.org/10.1016/0197-0070(89)90212-X.

Stubbs, Margaret L. 2008. "Cultural Perceptions and Practices around Menarche and Adolescent Menstruation in the United States." Annals of the New York Academy of Sciences 1135 (1): 58-66. https://doi.org/10.1196/annals.1429.008.

Uskul, Ayse K. 2004. "Women's Menarche Stories from a Multicultural Sample." Social Science \& Medicine 59 (4): 667-79. https://doi.org/10.1016/j. socscimed.2003.11.031.

Ussher, Jane M., and Janette Perz. 2013. "PMS as a Gendered Illness Linked to the Construction and Relational Experience of Hetero-femininity." Sex Roles 68 (1-2): 132-50. https://doi.org/10.1007/s11199-011-9977-5.

White, Lisandra Rodriguez. 2013. "The Function of Ethnicity, Income Level, and Menstrual Taboos in Postmenarcheal Adolescents' Understanding of Menarche 
and Menstruation." Sex Roles68 (1-2): 65-76. https://doi.org/10.1007/ s11199-012-0166-y.

Wilson, Ellen K., Barbara T. Dalberth, and Helen P. Koo. 2010. "'We're the Heroes!': Fathers' Perspectives on Their Role in Protecting their Preteenage Children from Sexual Risk." Perspectives on Sexual and Reproductive Health 42 (2): 117-24. https://doi.org/10.1363/4211710.

Wong, Wing Chi, Mei Kuen Li, Wai Ying Veronica Chan, Yuen Yu Choi, Chi Hung Sandra Fong, Ka Wah Kara Lam, Wun Chi Sham et al. 2013. "A Cross-Sectional Study of the Beliefs and Attitudes towards Menstruation of Chinese Undergraduate Males and Females in Hong Kong." Journal of Clinical Nursing 22 (23-24): 3320-27. https://doi.org/10.1111/jocn.12462.

Wright, Paul J. 2009. "Father-Child Sexual Communication in the United States: A Review and Synthesis." Journal of Family Communication 9 (4): 233-50. https://doi.org/10.1080/15267430903221880.

Wyckoff, Sarah C., Kim S. Miller, Rex Forehand, J. J. Bau, Amy Fasula, Nicholas Long, and Lisa Armistead. 2008. "Patterns of Sexuality Communication between Preadolescents and Their Mothers and Fathers." Journal of Child and Family Studies 17 (5): 649-62. https://doi.org/10.1007/s10826-007-9179-5.

Open Access This chapter is licensed under the terms of the Creative Commons Attribution 4.0 International License (http://creativecommons.org/licenses/ by $/ 4.0 /$ ), which permits use, sharing, adaptation, distribution and reproduction in any medium or format, as long as you give appropriate credit to the original author(s) and the source, provide a link to the Creative Commons license and indicate if changes were made.

The images or other third party material in this chapter are included in the chapter's Creative Commons license, unless indicated otherwise in a credit line to the material. If material is not included in the chapter's Creative Commons license and your intended use is not permitted by statutory regulation or exceeds the permitted use, you will need to obtain permission directly from the copyright holder.

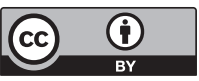

